\title{
INDICADORES DE FLUXO ESCOLAR E POLÍTICAS EDUCACIONAIS: AVALIAÇÃO DAS ÚLTIMAS DÉCADAS
}

\author{
FERNANDO TAVARES JÚNIOR \\ VICTOR BASÍLIO FARIA \\ MARCOS ALVES DE LIMA
}

1 Este trabalho é derivado do Projeto "Análise da evolução da Educação Básica no Brasil a partir dos indicadores de fluxo e proficiência", vinculado ao Programa Observatório da Educação que conta com apoio da Coordenação de Aperfeiçoamento de Pessoal de Nível Superior (Capes) e do Instituto Nacional de Estudos e Pesquisas Educacionais (Inep). Sua versão preliminar foi apresentada na VI Reunião Anual da Associação Brasileira de Avaliação Educacional (Abave). Os autores agradecem aos participantes, em especial ao Prof. Rubem Klein (debatedor na Abave), pelas valiosas contribuições, comentários e críticas. As investigações continuarão, conforme cronograma do Projeto, nos próximos anos, quando serão apresentados aprofundamentos decorrentes.

\section{RESUMO}

A discussão e crítica à estimação oficial dos indicadores de rendimento escolar no Brasil, em especial às taxas de aprovação, repetência e evasão, é antiga. O Profluxo (FLETCHER, RIBEIRO, 1989) foi proposto como um modelo matemático capaz de aprimorar a estimação dessas taxas e demonstrou que o maior problema não era a evasão, como antes se acreditava, mas a elevada repetência. Demandas contemporâneas motivaram a proposição de aprimoramentos na direção da parcimônia, do ajuste aos dados empíricos e da aplicação em avaliações de políticas educacionais. A partir do Profluxo, propôs-se o modelo Profluxo ${ }^{\underline{a}}$, em equação única de três parâmetros. Observou-se que o modelo Profluxo $0^{\underline{a}}$ modela melhor os dados e permite interpretação mais ajustada à análise de políticas, através de avanços na análise do interstício etário e nas propriedades dos parâmetros. Através dele, observou-se que a educação brasileira, nas últimas décadas, aprimorou o acesso, manteve baixa a evasão e diminuiu substancialmente a repetência, mas ainda há muito a ser feito.

PALAVRAS-CHAVE DESIGUALDADES SOCIAIS • RENDIMENTO ESCOLAR • REPETÊNCIA • EVASÃO ESCOLAR. 


\section{RESUMEN}

La discusión y la crítica en torno de la estimación oficial de los indicadores de rendimiento escolar en Brasil, en particular, de los índices de aprobación, de repitencia y de deserción son antiguas. El "Profluxo" (FLETCHER, RIBEIRO, 1989) se propuso como un modelo matemático capaz de mejorar la estimación de estos indicadores y mostró que el mayor problema no era la deserción, como se creía anteriormente, sino la alta repitencia. Las demandas contemporáneas motivaron la propuesta de un perfeccionamiento en dirección de la parsimonia, del ajuste a los datos empíricos $y$ de la aplicación en evaluaciones de politicas educativas. A partir del "Profluxo", se propuso el modelo "Profluxoa" en una ecuación única de tres parámetros. Se observó que este modelo organiza mejor los datos y permite una interpretación más ajustada al análisis de políticas, a través de avances en los análisis del intersticio etario y en las propiedades de los parámetros. Se observó también que la educación brasileña, en las últimas décadas, mejoró el acceso, mantuvo baja la deserción y disminuyó substancialmente la repitencia, pero aún queda mucho por hacer para elevar la aprobación y mejorar el pasaje de los alumnos.

PALABRAS CLAVE DESIGUALDADES SOCIALES • RENDIMIENTO ESCOLAR • REPITENCIA • EVASIÓN ESCOLAR.

\section{ABSTRACT}

The debate around official indicators of school performance (student flow) in Brazil goes back to the 1940s. The Profluxo (FLETCHER, RIBEIRO, 1989) was proposed as a mathematical model to improve the estimation of these rates and showed that the biggest problem was not dropout, as was previously believed, but high repetition rates. Contemporary demands motivated improvements toward parsimony, an adjustment to empirical data and an application in the assessment of educational policies. The Profluxo, generated the Profluxoa, in a single equation of three parameters (instead of a double equation with four parameters). It was observed that the new model improves data modelling and allows for a better interpretation of analyses of policies through advances in the analysis of age ranges and in the properties of the parameters. It was observed that Brazilian education, in recent decades, has improved access, maintained lower dropout, and repetition rates have decreased substantially, but much remains to be done. 


\section{INTRODUÇÃO}

O modelo Profluxo pertence a uma classe de modelos matemáticos formais, proposto no Brasil na década de 1980, com o objetivo de aprimorar a estimação de indicadores de rendimento escolar, em especial das taxas de aprovação, repetência e evasão. A crítica à estimação oficial dessas taxas pelo Ministério da Educação remonta à década de 1940 (FREITAS, 1940, 1947). No início da década de 1980, publicaram-se obras exemplares sobre o tema, como a resenha de Brandão (1983), que evidenciou as graves limitações do fluxo educacional no Brasil. A evasão e a repetência aparecem severamente marcadas por níveis elevados e quase insensibilidade às medidas políticas então adotadas. Nesse mesmo período, Fletcher (1985a) publica um primeiro ensaio sobre uma nova modelagem dos dados educacionais brasileiros e, logo em seguida, outro (FLETCHER, 1985b), sobre o alto volume da repetência nas séries iniciais, como um problema grave que era mal dimensionado e, também por isso, estava sendo negligenciado pelas políticas educacionais. Também nessa época, Silva e Souza (1986) propõem um modelo para análise da estratificação educacional. O modelo 
proposto era ainda um modelo logístico, cuja "preocupação fundamental era a relação entre a origem social e a realização educacional" (p. 49), em que analisava a "influência das variáveis de origem social sobre as chances de progressão escolar" (p. 56), já sob influência dos modelos de Mare (1980). A análise da realização educacional já apontava os efeitos perversos da reprodução social operada pelo sistema de ensino, mas não instruíam ainda a crítica às estatísticas oficiais de fluxo.

Logo depois, Fletcher e Ribeiro (1987) publicam o primeiro ensaio conjunto acerca dos problemas da Educação Básica, então ensino de primeiro grau, no Brasil. Em seguida, Fletcher e Ribeiro (1989) publicam a versão original do Profluxo, em trabalho para a Unesco que, infelizmente, teve pouca repercussão no Brasil. No entanto, foi através da proposição do Profluxo (FLETCHER, RIBEIRO, 1989) que se demonstrou o maior equívoco das estatísticas oficiais, que acabavam por instruir equivocadamente as políticas educacionais no país. O debate ganhou maior ressonância através da publicação da Pedagogia da Repetência (RIBEIRO, 1991). Estava então claro que o maior problema do sistema educacional brasileiro não era a evasão, como antes se acreditava, mas as elevadas taxas de repetência. Foram apontadas falhas estruturais na contabilidade de dados por parte do Ministério da Educação, o que comprometia gravemente a produção de indicadores educacionais confiáveis. O erro foi mais observado nas discrepâncias da evasão entre 1a e 2a séries, consequência da dupla contagem dos alunos nos censos escolares. Ao final de cada ano, os pais matriculavam seus filhos em outra escola ou a escola re-matriculava os alunos repetentes como alunos novos, o que subestimava a repetência e superestimava a evasão.

Nesse mesmo ano, outros dois trabalhos (KLEIN, RIBEIRO, 1991; FLETCHER,1991) ampliaram a discussão e o tema do fluxo ocupou lugar central no debate educacional brasileiro. A partir de então, foram implementadas várias políticas públicas para correção de fluxo, diminuição da repetência e melhoria da eficiência do sistema educacional. Estava preparado o terreno para a enorme expansão educacional na década de 1990 . Desde então, o sistema educacional brasileiro passou a ser analisado por outros prismas. Vários autores (KLEIN, 2003; GOLGHER, 2004; GOLGHER, RIOS-NETO, 2005; RIOS-NETO et al., 2005; BARROS, MENDONÇA, 1998; SOARES, 2002) analisaram as estatísticas, revisa- 
ram o método e propuseram novas formas de avaliação do fluxo para superação das inconsistências dos dados antes observadas.

O próprio MEC alterou sua forma de estimar as estatísticas de rendimento. Na Geografia da Educação Brasileira (INEP, 2002), principal diagnóstico da educação nacional e melhor síntese de indicadores educacionais oficiais, o fluxo aparece definido de forma completamente distinta. Essa transformação ocorrida nos anos 1990 em grande parte se deve à incorporação das críticas oriundas dos trabalhos acima citados, em especial os referentes ao Profluxo. Referência desse processo é a publicação (KLEIN, 2003) da forma consolidada de produção de indicadores e metodologia de cálculo do fluxo escolar. O avanço mais recente nessa direção é decorrente da alteração da produção do Censo Escolar, cuja unidade de análise original é a escola, para o EducaCenso, que incorpora a possibilidade de múltiplas unidades de análise, em arquitetura hierárquica e multidimensional, com a possibilidade de registro individual.

Devido à complexidade e longevidade da estimação, houve ponderações ao modelo que motivaram a proposição de ajustes na direção da parcimônia, da melhoria no ajuste e na aplicação em avaliações de políticas educacionais, através de avanços na análise do interstício etário e nas propriedades dos parâmetros. A principal crítica ao modelo (BARROS, MENDONÇA, 1998) refere-se à superestimação da repetência. No entanto, tal crítica não aponta um erro no modelo, mas uma diferença nos resultados entre o modelo proposto pelos autores e os resultados do Profluxo. De fato, este último tende a analisar o fluxo educacional de forma sistêmica e cumulativa, sem considerar variações pontuais (em cada coorte) destoantes da tendência geral (para o conjunto das coortes). No entanto, ao considerar o volume geral de matrículas mensuradas através de dados demográficos, de fato observam-se dois fatos incontestáveis: (1) as matrículas efetivamente verificadas pelas Pnads (em setembro) são significativamente inferiores às matrículas computadas pelo MEC (maio); ainda assim, (2) o volume geral de matrículas decorrentes de reprovações, sejam singulares ou sucessivas, sejam de repetência "tradicional" (reprovação ao final do ano por insuficiência no desempenho) ou repetência branca (decorrente de evasão antes de efetivar-se a reprovação por desempenho), é maior do que as verificadas pontualmente pelas escolas. 
De toda essa discussão, surgiu a motivação para a proposta do modelo Profluxo ${ }^{a}$, também a partir da Pesquisa Nacional por Amostras de Domicílios (Pnad) e utilizando os fundamentos do Profluxo original, mas em equação única de três parâmetros, em vez de duas equações e quatro parâmetros. Este trabalho objetiva então descrever a proposta de um novo modelo (Profluxo ${ }^{\mathrm{a}}$ ) mais parcimonioso e ajustado para estimação das taxas de fluxo, inspirado no modelo original do Profluxo. A proposta desse modelo objetiva também adequá-lo a demandas atuais de análise e avaliação de políticas educacionais, através da análise de parâmetros que tenham maior significado educacional e político, tendo em vista a democratização da educação pública no Brasil.

\section{A MODELAGEM DO FLUXO ESCOLAR}

Um dos mais graves problemas do sistema educacional brasileiro é a interrupção no fluxo escolar normal, ou seja, quando o aluno é reprovado ou abandona a série em curso. Segundo a Geografia da Educação Brasileira (INEP, 2002), a dificuldade em se seguir um fluxo escolar normal aparece mais no primeiro ano de cada etapa escolar. Em situações ideais, seria observado um gráfico próximo ao gráfico abaixo: todos os alunos entrariam no sistema de ensino na idade adequada e seriam aprovados, não havendo reprovação ou evasão.

GRÁFICO 1 - Ilustração "situação ideal”

Proporção de aprovados na 1aㅗ série do Ensino Fundamental por idade

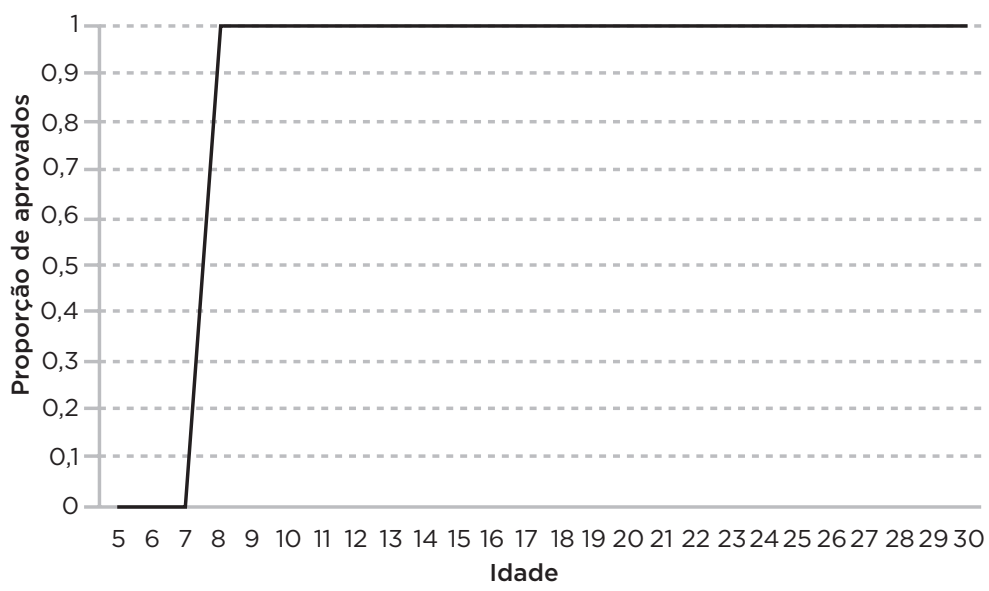


Para Fletcher e Castro (1993), o exame das estatísticas educacionais realizado sob um prisma diferenciado possibilita a visualização de problemas diferentes dos que são amplamente divulgados. Os determinantes de um bom desempenho não são totalmente acadêmicos e nem apenas de domínio cognitivo, pois as formas de se avaliar o aluno podem carecer de fidedignidade. Além disso, a repetência não melhora o desempenho nem reduz as diferenças na sala de aula. A repetência prejudica o autoconceito e o relacionamento social do aluno (SOARES, 2007). Também por isso, o debate sobre a melhor forma de calcular o fluxo escolar está presente na agenda de pesquisas da educação brasileira com vigor atual (BELTRÃO, CAMARANO, KANSO, 2002; FERNANDES, 2007; FLETCHER, 2005; RIGOTTI, 2001; SILVA, HASENBALG, 2002; dentre tantos outros). Na década de 1980, vários autores (SILVA E SOUZA, FLETCHER, KLEIN, RIBEIRO) destacaram que, com base na idade e no grau das declarações, junto com variáveis classificatórias, a estimação do fluxo escolar pode ser derivada de qualquer censo ou sondagem em larga escala em todo o país, em qualquer ano; podendo ser usado, também, para analisar as tendências longitudinais no desempenho do sistema. De forma geral, os indicadores de fluxo são calculados em termos de intervalo de anos, pois apresenta de forma sincronizada o tempo médio que o aluno permanece no sistema educacional e, nesse período, o número de séries efetivamente concluídas (INEP, 2002). Mediante essa avaliação calculam-se três taxas: promoção, retenção e evasão (abandono). Em relação ao sistema, importa observar sua eficiência ao converter matrículas novas em uma série em matrículas novas na série posterior, no ano seguinte. Por outro lado, importa também mensurar o volume das matrículas que é derivado de reprovações, o que representa a necessidade de enorme reinvestimento em função de entraves de qualidade.

\section{O MODELO}

Sabe-se que as curvas dos indicadores de rendimento (promoção, retenção e evasão) se aproximam de funções logísticas (ogiva), ou seja, com crescimento perene, porém com a diferença de apresentarem uma tendência de "queda" na parte final 
dos dados nas idades mais avançadas em função de o modelo englobar dados de diversos anos consecutivos. O modelo tradicional do Profluxo consiste da multiplicação de duas equações, a primeira equação para modelar o crescimento contínuo dos dados até certa idade, quando se alcança o topo do acesso, e a segunda equação para modelar a "queda" que ocorre na parte final, nas idades mais elevadas. Atualmente notamos que a segunda equação não é conditio sine qua non para estimação e modelagem dos dados, visto que as curvas atuais têm a tendência de cada vez mais se estabilizarem, decorrência dos avanços educacionais verificados nas últimas décadas. Assim, duas décadas depois da proposta do modelo, a primeira equação que dá origem à curva de "ogiva” é suficiente para demonstrar a tendência de cada curva, porém notamos que são necessárias mudanças para que o topo seja limitado para cada ano e série, visto que a curva logística tende ao pleno (1), mesmo com o avanço etário, que mensura a realização observada em anos anteriores. Utilizam-se, para os ajustes das taxas de participação dos ingressos, as equações do Profluxo como bem definidas por Fletcher e Ribeiro (1989). A proporção, $\mathrm{I}_{\mathrm{i}, \mathrm{k}}$ de indivíduos em uma determinada idade $\mathrm{i}$, cuja última série cursada é ${ }_{k}$, pode ser descrita pelo produto de duas frações:

$$
\begin{gathered}
\text { EQuaÇÃo (1) - Profluxo } \\
I_{\mathrm{i}, \mathrm{k}}=\mathrm{P}_{\mathrm{i}, \mathrm{k}} \times \mathrm{L}_{\mathrm{i}, \mathrm{k}}=\frac{2}{1+\exp \left(\mathrm{ai}^{-b}\right)} \times \frac{1}{1+\exp (\mathrm{c}+\mathrm{di})}
\end{gathered}
$$

$\mathrm{P}_{\mathrm{i}, \mathrm{k}}$ é responsável pela curva logística (ogiva), que ajusta a massa de dados em um crescimento acumulativo, e $\mathrm{L}_{\mathrm{i}, \mathrm{k}}$ é responsável pelo ajuste da parte final dos dados, onde se registra queda nas proporções avaliadas. Nas expressões acima, $a, b, c \mathrm{e}$ $d$ são parâmetros a serem determinados por métodos matemáticos e estatísticos. Na primeira equação, o parâmetro "a" modela principalmente a idade inicial de entrada na série. O parâmetro "b" modela a velocidade de crescimento ou inclinação máxima da curva. Na segunda equação, o parâmetro "c" modela a velocidade da diminuição dos valores da curva, ou "segunda inclinação"; enquanto o parâmetro "d" altera o ponto de partida para a diminuição dos valores da curva. 
O gráfico abaixo permite a comparação entre os dados empíricos, que aqui instruem a produção do que chamamos de "curvas reais", e os dados estimados, que projetam a chamada "curva ajustada".

GRÁFICO 2 - Comparação curvas reais e curvas ajustadas

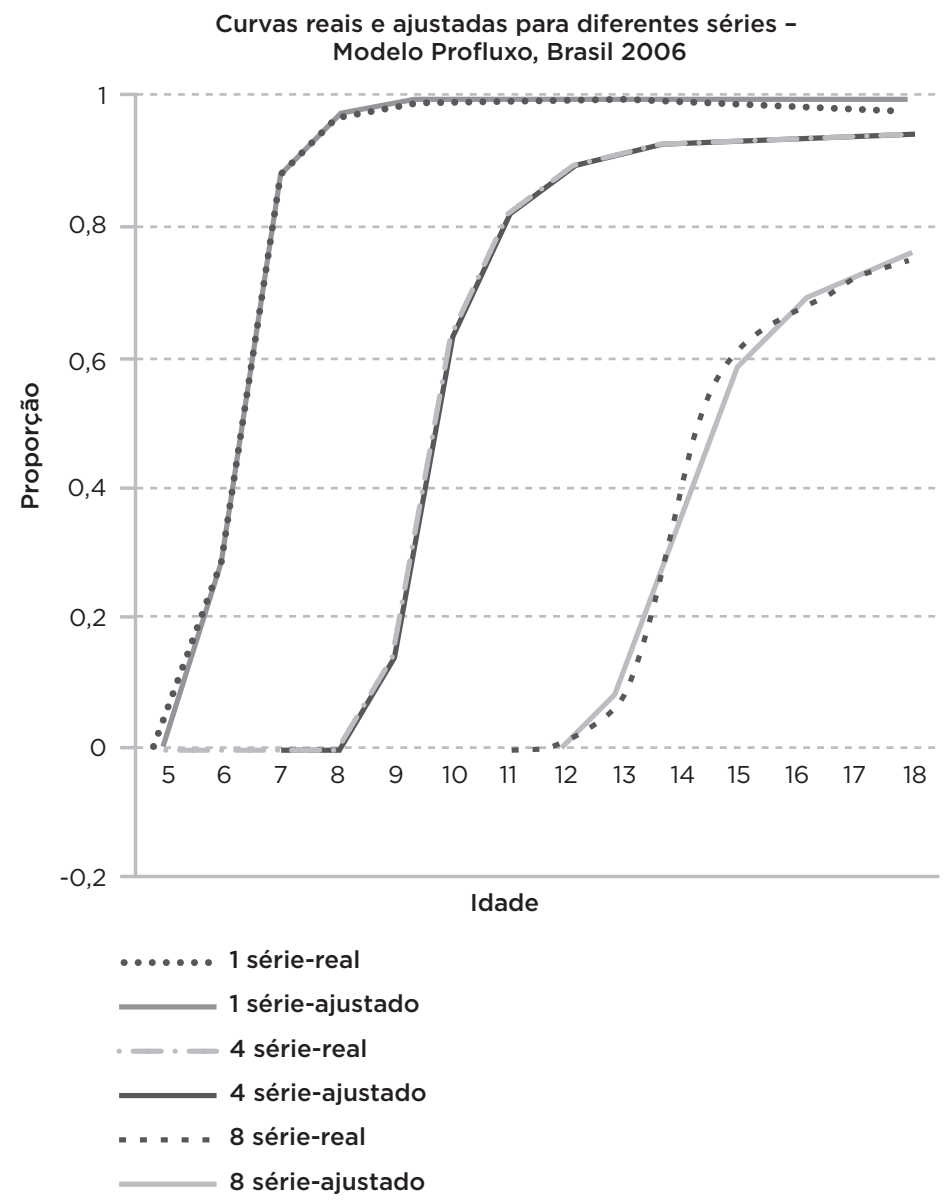

Essa "queda" da curva nas idades mais avançadas acontece em função de o modelo englobar dados de diversos anos consecutivos, porém notamos que, para os dias atuais, a segunda parte da equação não é sine qua non ao ajuste, tal como era nas décadas anteriores, visto que as curvas tendem à estabilidade, em especial se considerados intervalos etários não tão largos como antes, quando em geral abarcava-se um interstício de 25 anos (dos 5 aos 30 anos de idade). Isso também gera repercussões 
na análise das políticas, uma vez que se misturam efeitos de diferentes ciclos políticos e de gestão.

Propõe-se um modelo mais parcimonioso, aqui chamado de Profluxo ${ }^{\text {a }}$, baseado no modelo original do Profluxo, com ajustes no intervalo etário e na estimação das equações. O Profluxo ${ }^{a}$ é proposto com apenas uma equação (logística) ajustando a grande massa de dados. Para aprimorar o ajuste do modelo aos dados, propõe-se que a constante “ 1 ”, prevista no denominador, seja modelada por outro parâmetro, “c”, que limita o topo da ogiva. Assim, a proporção, $I_{i, k}$ de indivíduos em uma determinada idade $i$, cuja última série cursada é ${ }_{\mathrm{K}}$, poderia ser descrita pela fração:

$$
\begin{aligned}
& \text { EQUAÇÃo (2) - PROFLUXO } \\
& \qquad I_{i, k}=P_{i, k}=\frac{2}{c+\exp \left(a i^{-b}\right)}
\end{aligned}
$$

Nesse formato, o parâmetro "a” continua modelando a idade inicial de entrada na série, ou seja, a idade de ingresso. Quanto maior esse parâmetro, melhor o desempenho do sistema educacional, em especial por inserir as crianças na educação regular na idade correta. O parâmetro " $b$ " modela a velocidade de crescimento da curva, ou seu ângulo máximo de inclinação. Quanto maior esse parâmetro, mais inclinada é a curva e mais eficiente é o sistema. Logicamente que não é possível a inclinação máxima, mas quanto mais próximo de um ângulo reto, mais rapidamente os alunos tendem a completar a transição para a série seguinte. Por fim, o parâmetro "c" modela o topo de cada curva, avaliando o acesso e o alcance dos sistemas educacionais. Quanto menor seu valor, melhor o desempenho do sistema, ou seja, menor é a restrição ao fluxo. Após a proposição, verificou-se que o Profluxo ${ }^{a}$ modela melhor os dados (em relação ao Profluxo original) e, além disso, é mais parcimonioso, visto que possui apenas uma equação e três parâmetros, o que torna a estimativa mais simples.

A tabela seguinte traz um exemplo que permite a comparação entre os dados empíricos e os dados estimados. Foram escolhidas a $1^{\mathrm{a}}, 4^{\mathrm{a}}$ e $8^{\mathrm{a}}$ séries fundamentais. Tal escolha foi motivada pela importância que cada uma exerce em determinado 
ciclo escolar do aluno, bem como por concentrarem os maiores desafios do fluxo. Observamos que as estimativas estão muito próximas da observação empírica e, se não considerarmos a queda nos dados brutos, o modelo se ajusta com maior exatidão.

TABELA 1 - Comparação dados brutos com o Profluxoa

\begin{tabular}{|c|c|c|c|c|c|c|}
\hline \multicolumn{7}{|c|}{ PROPORÇÃO DE INGRESSOS EM DIFERENTES SÉRIE, BRASIL-2006 } \\
\hline \multirow{2}{*}{ Idade } & \multicolumn{2}{|c|}{$1^{\text {a }}$ série } & \multicolumn{2}{|c|}{$4^{\text {a }}$ série } & \multicolumn{2}{|c|}{$8^{a}$ série } \\
\hline & Real & Proposto & Real & Proposto & Real & Proposto \\
\hline 5 & $3,23 \%$ & $0,00 \%$ & - & - & - & - \\
\hline 6 & $28,40 \%$ & $28,31 \%$ & - & - & - & - \\
\hline 7 & $86,04 \%$ & $86,71 \%$ & - & - & - & - \\
\hline 8 & $96,90 \%$ & $95,86 \%$ & $1,22 \%$ & $0,00 \%$ & - & - \\
\hline 9 & $98,43 \%$ & $97,85 \%$ & $14,18 \%$ & $14,22 \%$ & - & - \\
\hline 10 & $98,97 \%$ & $98,45 \%$ & $62,44 \%$ & $62,23 \%$ & - & - \\
\hline 11 & $99,13 \%$ & $98,67 \%$ & $81,43 \%$ & $82,05 \%$ & - & - \\
\hline 12 & $99,44 \%$ & $98,76 \%$ & $88,83 \%$ & $89,05 \%$ & $0,92 \%$ & $0,00 \%$ \\
\hline 13 & $99,32 \%$ & $98,81 \%$ & $92,77 \%$ & $91,91 \%$ & $8,85 \%$ & $9,02 \%$ \\
\hline 14 & $98,92 \%$ & $98,83 \%$ & $94,01 \%$ & $93,25 \%$ & $41,83 \%$ & $41,67 \%$ \\
\hline 15 & $98,36 \%$ & $98,84 \%$ & $94,13 \%$ & $93,93 \%$ & $60,70 \%$ & $60,06 \%$ \\
\hline 16 & $98,29 \%$ & $98,85 \%$ & $93,66 \%$ & $94,31 \%$ & $66,55 \%$ & $68,05 \%$ \\
\hline 17 & $97,84 \%$ & $98,85 \%$ & $94,52 \%$ & $94,53 \%$ & $71,98 \%$ & $71,87 \%$ \\
\hline 18 & $97,36 \%$ & $98,86 \%$ & $94,11 \%$ & $94,66 \%$ & $74,64 \%$ & $73,89 \%$ \\
\hline
\end{tabular}

Em relação à análise dos parâmetros $a, b$ e $c$, observou-se que desempenham adequadamente seu papel, como descrito anteriormente, mudando a idade inicial de acesso, alterando a velocidade do crescimento; no caso, "b" diminui de acordo com o aumento da série, ou seja, a curva cresce mais lentamente à medida que a série aumenta e "c" altera o topo da curva, que são inversamente proporcionais. Assim como na tabela, através do gráfico, observamos que o modelo Profluxo ${ }^{\mathrm{a}}$ se ajustou bem aos dados: 


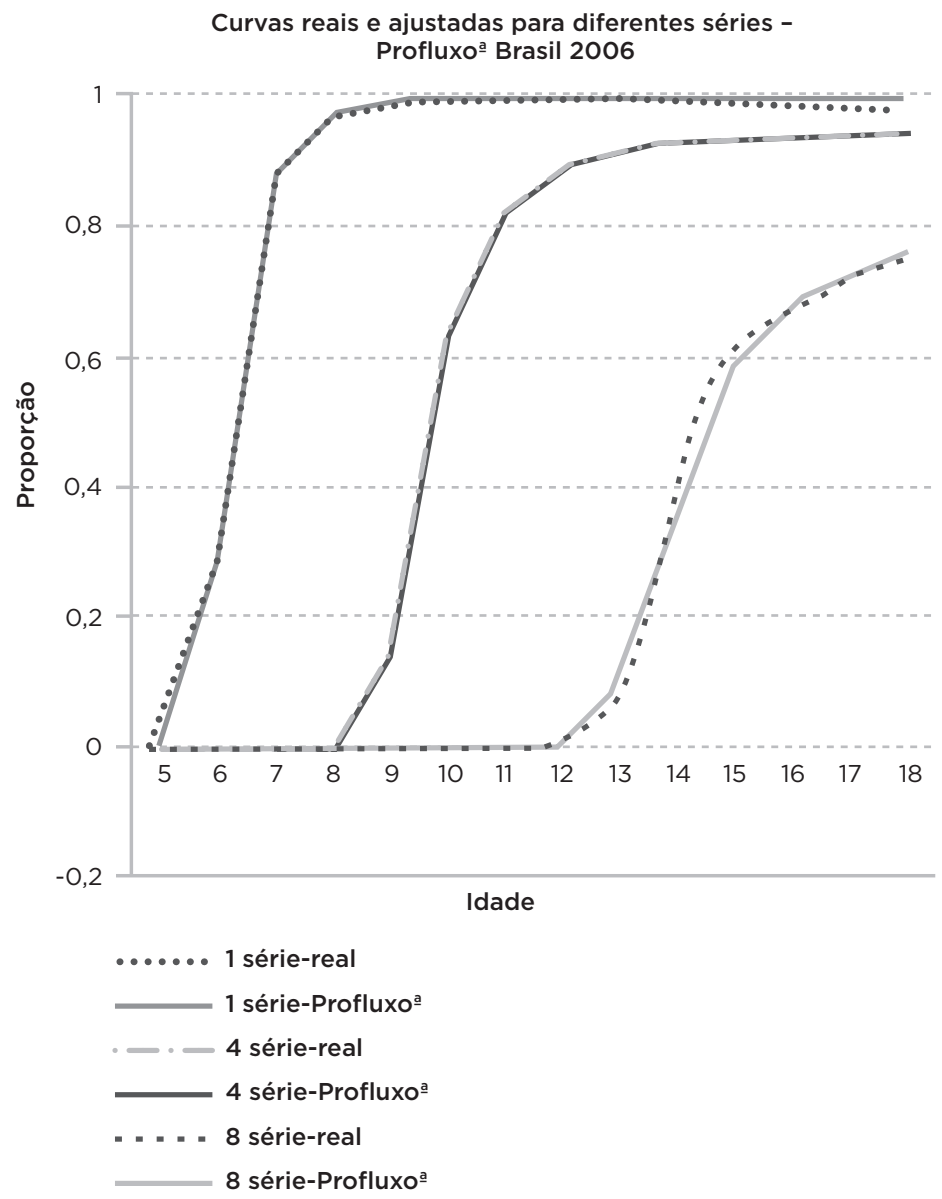

Se considerarmos que, para os dias atuais, o declínio do acesso tende a não ocorrer em função do avanço etário tão acentuadamente como antes ocorria, a curva de ajuste proposta tende a sobrepor com maior precisão à curva empírica. Tais curvas são obtidas através da modelagem dos dados empíricos em função da Equação 2 descrita anteriormente. Para efeitos de estimação das taxas, interessa-nos mais o cálculo das áreas entre uma curva e sua subsequente, ou seja, a área que mensura o volume de matrículas/indivíduos afetados por cada um dos fenômenos: promoção, retenção e evasão.

Isso é implementado através de cálculo de integrais definidas. Denotando Ingi,k, os ingressos com idade ${ }_{i}$ na série ${ }_{k}$. Aprov $_{i, k}$ os aprovados com idade ${ }_{i}$ na série ${ }_{k}$, e obtendo Ing ${ }_{i, k}$ 
através do cálculo $\mathrm{f}\left(\operatorname{Ing}_{\mathrm{i}, \mathrm{k}}\right)=\mathrm{f}\left(\operatorname{Ing}_{\mathrm{i}-1, \mathrm{k}}\right)$, podemos calcular cada indicador (promoção, reprovação e evasão) através de taxas. Considerando que os alunos novos em uma determinada série k são os aprovados da série k-1 que não evadiram do sistema, temos então a seguinte igualdade: promoção $=\operatorname{Ing}_{i, \mathrm{k}}-$ Ing $_{\mathrm{i}, \mathrm{k}}$. Os retidos em determinada série $\mathrm{k}$ são obtidos através de: Ing $_{\mathrm{i}, \mathrm{k}}-\operatorname{Aprov}_{\mathrm{i}, \mathrm{k}}$. Por fim, os alunos que evadiram do sistema são definidos a partir do último intervalo etário (indivíduos totais) pela área $=\operatorname{Aprov}_{i, \mathrm{k}}-\operatorname{Ing}_{\mathrm{i}, \mathrm{k}+1}$

Cada uma dessas áreas representa um volume de matrículas ou percentual de indivíduos afetados por determinada alteração de status: estar (ou não) matriculado na série K, ter (ou não) escolaridade equivalente a anos de estudo $\mathrm{E}$. Tais valores representam a diferença entre cada área, portanto para transformá-los em taxas devemos dividi-los pela área total que os compõe, de onde se estima o total de matrículas.

\section{RESULTADOS}

Como acima citado, as taxas são calculadas através da área de cada indicador dividida pela área total dos três indicadores. Para ilustrar tal fato, escolhemos cinco anos (1976, 1982, 1986, 1996 e 2006). A opção por esses anos se dá pela possibilidade do início da série histórica de dados apta à estimação (1976 é o primeiro ano de referência disponível); pela comparabilidade viabilizada em função da estabilidade da série (a partir de 2007 houve alteração na consolidação dos dados de matrícula em função da contabilidade de anos/séries); pelo significativo intervalo (10 anos) que torna possível a observação de alteração nas tendências e, no caso de 1982, pela possibilidade de comparar os resultados com as primeiras estimações do modelo original do Profluxo. As tabelas seguintes trazem os resultados sintéticos para o ensino fundamental: 
TABELA 2 - Fluxo educacional estimado através do modelo Profluxoa, Brasil 1976

\begin{tabular}{|c|c|c|c|c|c|c|c|c|}
\hline \multicolumn{9}{|c|}{1976} \\
\hline & $1^{a}$ série & $2^{\text {a }}$ série & 3a série & $4^{a}$ série & $5^{\text {a }}$ série & 6a série & 7ạ série & 8a série \\
\hline Promoção & $57,15 \%$ & $63,33 \%$ & $65,17 \%$ & $51,80 \%$ & $64,15 \%$ & $63,91 \%$ & $63,73 \%$ & $51,67 \%$ \\
\hline Retenção & $41,39 \%$ & $32,50 \%$ & $27,58 \%$ & $29,50 \%$ & $25,34 \%$ & $30,43 \%$ & $31,30 \%$ & $38,27 \%$ \\
\hline Evasão & $1,46 \%$ & $4,17 \%$ & $7,25 \%$ & $18,70 \%$ & $10,51 \%$ & $5,66 \%$ & $4,97 \%$ & $10,06 \%$ \\
\hline
\end{tabular}

TABELA 3 - Fluxo educacional estimado através do modelo Profluxoa, Brasil 1982

\begin{tabular}{|c|c|c|c|c|c|c|c|c|}
\hline \multicolumn{9}{|c|}{1982} \\
\hline & $1^{\mathrm{a}}$ série & $2^{a}$ série & 3a série & 4ª série & $5^{a}$ série & 6a série & 7ª série & 8asie \\
\hline Promoção & $39,94 \%$ & $63,58 \%$ & $67,26 \%$ & $62,65 \%$ & $60,41 \%$ & $74,62 \%$ & $78,31 \%$ & $50,03 \%$ \\
\hline Retenção & $58,67 \%$ & $32,67 \%$ & $25,53 \%$ & $20,03 \%$ & $31,19 \%$ & $17,30 \%$ & $13,30 \%$ & $22,92 \%$ \\
\hline Evasão & $1,39 \%$ & $3,75 \%$ & $7,21 \%$ & $17,32 \%$ & $8,40 \%$ & 8,०८\% & $8,39 \%$ & $27,05 \%$ \\
\hline
\end{tabular}

TABELA 4 - Fluxo educacional estimado através do modelo Profluxoa, Brasil 1986

\begin{tabular}{|c|c|c|c|c|c|c|c|c|}
\hline \multicolumn{9}{|c|}{1986} \\
\hline & $1^{1}$ série & $2^{a}$ série & 3a série & $4^{a}$ série & $5^{a}$ série & $6^{a}$ série & $7^{a}$ série & $8^{a}$ série \\
\hline Promoção & $60,36 \%$ & $60,77 \%$ & $69,39 \%$ & $62,76 \%$ & $76,54 \%$ & $62,97 \%$ & $77,02 \%$ & $49,39 \%$ \\
\hline Retenção & $37,95 \%$ & $35,76 \%$ & $24,35 \%$ & $22,26 \%$ & $12,39 \%$ & $28,92 \%$ & $14,62 \%$ & $26,30 \%$ \\
\hline Evasão & $1,69 \%$ & $3,47 \%$ & $6,26 \%$ & $14,98 \%$ & $11,07 \%$ & $8,11 \%$ & $8,36 \%$ & $24,31 \%$ \\
\hline
\end{tabular}

TABELA 5 - Fluxo educacional estimado através do modelo Profluxoa, Brasil 2006

\begin{tabular}{|c|c|c|c|c|c|c|c|c|}
\hline \multicolumn{9}{|c|}{2006} \\
\hline & $1^{a}$ série & $2^{a}$ série & 3a série & $4^{a}$ série & $5^{a}$ série & 6a série & $7^{a}$ série & $8^{a}$ série \\
\hline Promoção & $75,21 \%$ & $76,40 \%$ & $82,88 \%$ & $86,32 \%$ & $72,56 \%$ & $77,53 \%$ & $83,11 \%$ & $70,41 \%$ \\
\hline Retenção & $24,57 \%$ & $23,16 \%$ & $16,31 \%$ & $11,32 \%$ & $24,43 \%$ & $18,94 \%$ & $12,13 \%$ & $15,85 \%$ \\
\hline Evasão & $0,22 \%$ & $0,44 \%$ & $0,81 \%$ & $2,36 \%$ & $3,01 \%$ & $3,53 \%$ & $4,76 \%$ & $13,74 \%$ \\
\hline
\end{tabular}

O modelo Profluxo ${ }^{\mathrm{a}}$ mensura adequadamente as taxas de fluxo, modelando bem os dados empíricos e, ao mesmo tempo, simplificando sua estimação; atuando, assim, de forma coerente com a proposição original do Modelo Profluxo. Em relação aos dados e tendências gerais, observamos que a promoção entrou em acentuado declínio na década de 80 , chegando a patamares inferiores aos anteriormente verificados. As políticas de 
correção de fluxo e melhoria de eficiência implementadas nos anos 1990, no entanto, parecem ter dado resultado positivo, elevando consideravelmente a promoção. Ao observar as taxas relativas a 2006, pode-se constatar um progresso significativo ao longo dessas duas décadas. No entanto, o fluxo eficiente de estudantes é ainda um desafio à educação brasileira.

\section{CONSIDERAÇÕES FINAIS}

O modelo Profluxo ${ }^{\mathrm{a}}$ mostrou-se sintético, parcimonioso e muito bem ajustado aos dados, com estimativas de erro menores do que o modelo original do Profluxo. Sua aplicação aos dados de sucessivas Pnads permitiu análises múltiplas, tanto a clássica transposição de dados transversais para uso quasi-longitudinal, quanto principalmente o estudo das séries históricas dos indicadores de rendimento: evasão, promoção e retenção. Ao longo do tempo, foram verificados vários avanços. No entanto, uma análise mais criteriosa aponta para o caráter reprodutivo do sistema educacional brasileiro.

Os ganhos de acesso ao ensino fundamental ao longo dos anos de 1970 foram anulados pela acentuada perversão do fluxo escolar, verificada logo no início dos anos de 1980 . O acesso à primeira série até os 8 anos de idade saltou de $66 \%$ em 1976, para 80\% em 1982: um progresso considerável. No entanto, aos 9 anos apenas 52\% alcançavam a segunda série, tanto em 1976 quanto em 1982. Aos 10 anos, esse percentual subia um pouco (64\%), mas mantinha-se o mesmo para ambas as Pnads. Ou seja, na mesma proporção que a escola admitiu novos alunos, principalmente oriundos das camadas tradicionalmente mais excluídas (pobres, rurais, não escolarizadas, et al.), essa mesma escola os expulsou, agravando exponencialmente a reprovação. Essa reprovação, seja manifesta nas estatísticas oficiais ou mascarada pela evasão e encoberta pela dupla contagem de novatos, anulou os avanços obtidos pela expansão do sistema e ainda agravou seus problemas. Os custos sistêmicos com educação elevaram-se exponencialmente. As novas matrículas somaram-se às matrículas de repetentes sucessivos, criando a demanda perversa de recursos humanos e materiais suficientes para completar todo o $1^{\circ} \mathrm{Grau}$, mas que nem se aproximavam 
de tais resultados. Esses recursos e esforços produziram a escolarização de não mais que, em média, 3 ou 4 anos de estudo completos de uma geração inteira de semialfabetizados.

Mais uma vez reiterou-se no Brasil a perda de uma oportunidade histórica, produziu-se o desperdício de escolarização uma geração inteira, negando a amplas camadas da população o acesso ao direito básico de aprender. Durante anos, boa parte dessa crise era mascarada pela dupla contagem, pelas fraudes no lançamento dos dados, pela frágil consolidação das estatísticas oficiais. Papel histórico desempenhou a geração dos pioneiros da Avaliação Educacional no país, como Sérgio Costa Ribeiro, Phillip Fletcher, Rubem Klein, Nelson do Valle e Silva e outros. Sua crítica contumaz à desigualdade educacional no Brasil e à maquilagem dos indicadores oficiais proporcionou o avanço subsequente na produção de medidas, bem como a análise adequada da crise educacional.

O efeito excludente pela limitação do acesso nos anos de 1970 foi reproduzido pelo agravamento do fluxo escolar negativo no início dos anos de 1980, anulando as conquistas de acesso. Ao longo dos anos de 1990 foram implementadas medidas para correção do fluxo escolar. Destacam-se os projetos de adoção de ciclos de ensino, com especial atenção à alfabetização, múltiplos projetos de aceleração de aprendizagem para correção da distorção idade série e mesmo tentativas de aprovação automática. De fato, a primeira década deste século evidencia o progresso nessa temática. Os dados mais recentes estimados pelo Profluxo ${ }^{a}$ são significativamente melhores do que os da década anterior e exponencialmente mais eficientes do que os da década de 1980 .

No entanto, observou-se, nesse mesmo período, fenômeno similar ao ocorrido anteriormente. Os ganhos obtidos com a melhoria no fluxo foram em certa parte minimizados pela sucessiva queda na qualidade da educação. Embora não seja objeto específico deste trabalho, é de conhecimento amplo, principalmente entre avaliadores da educação, que as médias de proficiência observadas na escola pública brasileira são muito inferiores à esperada. Egressos do primeiro ciclo fundamental apresentam, em média, proficiência esperada para recém-alfabetizados. Egressos do ensino fundamental apresentam proficiência média próxima à esperada de egressos do 
primeiro ciclo. Egressos do ensino médio são, em média, proficientes tanto quanto deveriam ser antes de terem ingressado nesse nível.

A deterioração dos padrões de qualidade, desde que começaram a ser mensurados, evidencia comportamento parecido com o antes verificado em relação ao binômio acesso $\mathrm{x}$ fluxo: avança-se numa dimensão e retroage-se concomitantemente em outra, gerando resultados por vezes mais perversos do que o cenário anterior. Essa tendência só se reverteu em anos recentes. Se os anos de 1990 foram de sucesso nas políticas educacionais de democratização e de melhoria no fluxo, é preciso tornar essa década um período exemplar de políticas de melhoria concomitante de qualidade (aprendizagem) e fluxo.

A democratização da educação brasileira parece ser caracterizada por uma dualidade, um perfil estranho e dialético de realização social. Se por um lado avança na direção das principais demandas sociais, por outro, num mesmo movimento, também tende a anular esses avanços, gerando efeitos perversos em outra ponta. Tal traço acaba por reiterar a desigualdade, como elemento característico de nossa formação social. Os últimos 20 anos registraram vários esforços para melhoria do fluxo e, de fato, os indicadores melhoraram substancialmente. No entanto, são números que ainda impressionam por seu efeito iníquo. O filtro entre o ingresso e a conclusão do ensino fundamental é muito seletivo, produzindo enorme exclusão educacional. Ainda sem corrigir completamente esse problema, ao mesmo tempo em que ele era atacado gestava-se no interior do sistema de ensino uma severa deterioração da qualidade. O resultado conjunto desses dois processos é, ao final da primeira década do novo milênio, um sistema educacional ainda muito excludente: com qualidade muito baixa e fluxo ainda perverso, principalmente nas escolas que atendem à clientela de menor poder aquisitivo, o que tende a elevar a desigualdade de oportunidades, em especial a educacional.

Se a metáfora leninista de progresso aceitava alguma parcela de retrocesso, dando "um passo atrás, para dar dois passos à frente", parece ter sido muito mal compreendida e mal aplicada, pois parece que damos "um passo à frente, para dar dois passos para trás". Se isso é traço de nossa modernização conservadora, tal esperança ainda assim carece de melhor 
compreensão. É preciso alterar esse caminho. A adoção do Ideb, com a consequente valorização do fluxo e da qualidade, pode ser um passo significativo rumo a uma nova direção. No entanto, é preciso manter a atenção nessa tendência histórica e evitar sua reverberação em outras dimensões. Antes ainda, é preciso compreender como inaceitáveis tais indicadores de rendimento (fluxo) e desempenho (aprendizagem). A aceitação passiva de tais resultados fortaleceria a força motriz reprodutivista que ainda hoje opera da escola brasileira, através de sua "Pedagogia da Repetência".

\section{REFERÊNCIAS BIBLIOGRÁFICAS}

BARROS, Ricardo Paes; MENDONÇA, Rosane. Consequências da repetência sobre o desempenho educacional. Brasília: Ministério da Educação. Projeto de Educação Básica para o Nordeste, 1998.

BELTRÃO, Kaizô Iwakami; CAMARANO, Ana Amélia; KANSO, Solange. Ensino fundamental: diferenças regionais. Rio de Janeiro: Ipea, 2002.

(Texto para Discussão 935).

BRANDÃO, Zaia et al. Evasão e repetência no Brasil: a escola em questão.

Rio de Janeiro: Achiamé, 1983.

BRASIL. Ministério da Educação. Instituto Nacional de Estudos e Pesquisas Educacionais Anísio Teixeira. Geografia da educação brasileira. Brasília: Inep, 2002.

FERNANDES, Reynaldo. Índice de Desenvolvimento da Educação Básica (Ideb). Brasília: Inep, 2007. (Textos para Discussão).

FLETCHER, Phillip R. A demografia do desenvolvimento da educação no Brasil. Comparative and International Education Society. Stanford University, 2005. p. 1-31.

A mathematical model of school trajectory, repetition and performance of first level schooling in Brazil. Brasília: CNRH, 1985a.

. A Repetência no ensino de $1^{\circ}$ grau: um problema negligenciado da educação brasileira. Revista Brasileira de Administração da Educação, v. 3, n. 1, 1985b. Ipea, 1991.

Pesquisa Nacional de Avaliação do Perfil Cognitivo da População. Brasília:

FLETCHER, Phillip R.; CASTRO, Cláudio de Moura. Os Mitos, as estratégias e as prioridades para o ensino de $1^{\circ}$ grau. Estudos em Avaliação Educacional. São Paulo: Fundação Carlos Chagas, n. 8, p. 39-56, jul./dez. 1993.

FLETCHER, Phillip R.; RIBEIRO, Sérgio Costa. O Ensino de primeiro grau no Brasil de hoje. Em Aberto. Brasília: Inep, v. 6, n. 33, p. 1-10, jan./mar. 1987. 
Modeling Education System Performance with Demographic Data:

an introduction to the PROFLUXO Model. Paris: Unesco, 1989.

FREITAS, M. A. Teixeira de. Dispersão demográfica e escolaridade. Revista Brasileira de Estatística, v. 1, n. 3, p. 497-527, 1940.

FREITAS, M. A. Teixeira de. A Escolaridade média no ensino primário brasileiro. Revista Brasileira de Estatística, v. 8, n. 30-31, p. 395-474, 1947.

GOLGUER, André Braz. Modelo Profluxo e Indicadores Derivados. In: RIOS-NETO, Eduardo Luiz Gonçalves; RIANI, Juliana de Lucena Ruas (Org.). Introdução à demografia da educação. Campinas: Abep, 2004. p. 159-208.

GOLGUER, André Braz; RIOS-NETO, Eduardo Luiz Gonçalves. Uma comparação entre os modelos Profluxo e IPC quando aplicados a dados do sistema educacional brasileiro. Brasília: Inep, 2005.

KLEIN, Ruben. Produção e utilização de indicadores educacionais: metodologia de calculo de indicadores do fluxo escolar da educação básica. Revista Brasileira de Estudos Pedagógicos. Brasília, v. 84, n. 206-208, p. 107-157, 2003.

KLEIN, Ruben; RIBEIRO, Sergio Costa. O Censo educacional e o modelo de fluxo: o problema da repetência. Revista Brasileira de Estatística. Rio de Janeiro, v. 52, n. 197-198, p. 1-123, 1991.

MARE, Robert. Social background and school continuation decisions. Journal of the American Statistical Association, n. 75, p. 295-305, 1980.

RIBEIRO, Sérgio Costa. A Pedagogia da repetência. Estudos Avançados. São Paulo, v. 5, n. 12, p. 7-21, maio/ago. 1991.

RIGOTTI, J. I. R. A Transição da escolaridade no Brasil e as desigualdades regionais. Revista Brasileira de Estudos Populacionais. Campinas, v. 18, n. 1/2, p. 59-73, 2001.

RIOS-NETO, Eduardo et al. O Uso de modelos em demografia da educação: modelo Profluxo com dados das PNADs de 2001, 2002 e 2003. Belo Horizonte: Cedeplar - Convênio 29/2002, mar. 2005.

SILVA, Nelson do Valle; HASENBALG, Carlos. Recursos familiares e transições educacionais. Cadernos de Saúde Pública, n. 18, p. 67-76, 2001. (suplemento).

SILVA, Nelson do Valle; SOUZA, Alberto de Mello e. Um modelo para análise da estratificação educacional no Brasil. Cadernos de Pesquisa, n. 58, p. 49-57, ago.1986.

SOARES, Sergei. A Repetência no contexto internacional: o que dizem os dados de avaliações das quais o Brasil participa. Brasília: Ipea, 2007. (Texto para Discussão $n^{\circ} 1300$ ).

SOARES, Sergei; LIMA, Adriana Fernandes. A Mensuração da educação nas PNADs da década de 1990. Rio de Janeiro: Ipea, 2002. (Texto para Discussão nº 928). 
FERNANDO TAVARES JÚNIOR

Professor Adjunto do Departamento de Ciências Sociais (DCSO/ ICH) e Coordenador de Projetos do Centro de Políticas Públicas e Avaliação da Educação (CAEd) da Universidade Federal de Juiz de Fora (UFJF)

ftavares@caed.ufjf.br

\section{VICTOR BASÍLIO FARIA}

Estagiário de Pesquisa (CAEd) vinculado ao Projeto "Análise da evolução da Educação Básica no Brasil a partir dos indicadores de fluxo e proficiência” - Observatório da Educação Inep/Capes

victorbasilio@caed.ufjf.br

\section{MARCOS ALVES DE LIMA}

Bolsista de Iniciação Científica (Capes) vinculado ao Projeto "Análise da evolução da Educação Básica no Brasil a partir dos indicadores de fluxo e proficiência” - Observatório da Educação Inep/Capes

mlima@caed.ufjf.br 